\title{
Potential of eye tracking technology for assessment of performance and medical education in the field of anesthesia
}

\author{
Eunsoo Kim \\ Department of Anesthesia and Pain Medicine, Pusan National University School of Medicine, Busan, Korea
}

Eye tracking refers to the process of measuring either the gaze point or eye movement while an individual performs a task [1]. These measurements are performed by a device or computer equipped with an eye tracker, which consists of cameras, and projectors and utilizes image processing algorithms. In conjunction with ongoing advances in eye tracking methods and equipment, eye tracking technology has been applied in a growing number of diverse fields including psychology, neuroscience, marketing, product design, automotive research, and medicine [2]. In all of these fields, eye tracking technology is utilized on the basis of a relationship between what a subject is looking at and what he or she is paying attention to or thinking about at that point in time.

In the medical field, eye tracking has long been used as a useful tool in medical diagnosis, especially mental diseases such as schizophrenia [3], bipolar disorder [4], attention deficit hyperactivity disorder (ADHD) [5], autism [6] and Alzheimer's disease [7]. Various eye tracking techniques have been used for diagnostic purposes, ranging from simple methods such as pro-saccadic tasks, anti-saccadic tasks, and smooth pursuit tasks to more complicated methods such as visual search tasks and free observation [8].

While numerous studies have investigated the use of eye tracking to diagnose various diseases $[3-7,9,10]$, its role in medical therapy and treatment has not been well established due to

Corresponding author: Eunsoo Kim, M.D., Ph.D.

Department of Anesthesia and Pain Medicine, Pusan National University

School of Medicine, 179, Gudeok-ro, Seo-gu, Busan 49241, Korea

Tel: 82-51-240-7274, Fax: 82-51-242-7466

Email: eunsookim@pusan.ac.kr

ORCID: https://orcid.org/0000-0001-9978-4973

Korean J Anesthesiol 2018 August 71(4): 253-254

https://doi.org/10.4097/kja.d.18.00177 a relative lack of evidence. Patients with locked-in state amyotrophic lateral sclerosis (ALS) can use an eye tracking assistive device to communicate with their caregivers. This can improve quality of life in ALS patients, and reduce the burden on caregivers [11]. An eye tracker can reportedly help patients with eye cancer during radiotherapy by reducing the target volume size and concentrating the radiation beam on the lesion [12]. A recent clinical trial investigated the feasibility of early attention skill training via novel eye tracking technology and gaze-contingent training paradigms in infants at familial risk of ADHD [13].

Eye tracking technology can also reportedly yield information that is used for differentiating novices from experts by analyzing their visual patterns [14-17]. One systematic review suggests that eye tracking technology may be reliable tool for the assessment of surgeon skill [14]. In another study investigating chest X-ray interpretation for pneumothorax, it was found that the diagnostic accuracy of pneumothorax increased with experience, and that parameters derived from eye tracking were also significantly associated with diagnostic accuracy [15]. In the field of anesthesia, analysis of visual attention via eye tracking technology may be useful for the assessment of performance in ultrasound-guided regional anesthesia (UGRA). Harrison et al. [16] examined gaze-fixation heat map for comparing procedural expertise while performing simulated UGRA. In another study, Borg et al. [17] investigated the area of interest of anesthesiologists who were asked a standardized anatomy-based question related to ultrasound image that may be commonly encountered during UGRA. These studies presented that experts spent less unfocused time away a target compared to novices. Similarly, Schulz et al. [18] investigated the impact of experience on performance, physiological workload indicators, and distribution of visual attention during simulated critical incidents.

In this issue, King et al. [19] utilized eye tracking technology in a comparative evaluation of five malignant hyperthermia

(c) This is an open-access article distributed under the terms of the Creative Commons Attribution Non-Commercial License (http://creativecommons.org/ licenses/by-nc/4.0/), which permits unrestricted non-commercial use, distribution, and reproduction in any medium, provided the original work is properly cited. 
cognitive aids. This method may provide useful data for the development of new cognitive aids that could be helpful for patient care during critical events. In addition, a better understanding of the relationship between visual attention, situational awareness, and performance may result in improved monitoring interfaces and enhanced usability of anesthesia machines in the workplace $[20,21]$. In the field of anesthesia, the currently available evidence suggests that eye tracking is a promising area of research in terms of performance assessment and improvement of healthcare provider training.

\section{References}

1. Mele ML, Federici S. Gaze and eye-tracking solutions for psychological research. Cogn Process 2012; 13 Suppl 1: S261-5.

2. Duchowski AT. Diversity and types of eye tracking applications. In: Eye Tracking Methodology: Theory and Practice: Cham, Springer International Publishing, 2017. pp 247-8.

3. Diefendorf AR, Dodge R. An experimental study of the ocular reactions of the insane from photographic records. Brain 1908; $31: 451-89$.

4. García-Blanco A, Salmerón L, Perea M, Livianos L. Attentional biases toward emotional images in the different episodes of bipolar disorder: an eye-tracking study. Psychiatry Res 2014; 215: 628-33.

5. Tseng PH, Cameron IG, Pari G, Reynolds JN, Munoz DP, Itti L. High-throughput classification of clinical populations from natural viewing eye movements. J Neurol 2013; 260: 275-84.

6. Wang S, Jiang M, Duchesne XM, Laugeson EA, Kennedy DP, Adolphs R, et al. Atypical visual saliency in autism spectrum disorder quantified through model-based eye tracking. Neuron 2015; 88: 604-16.

7. Crutcher MD, Calhoun-Haney R, Manzanares CM, Lah JJ, Levey AI, Zola SM. Eye tracking during a visual paired comparison task as a predictor of early dementia. Am J Alzheimers Dis Other Demen 2009; 24: 258-66.

8. Harezlak K, Kasprowski P. Application of eye tracking in medicine: a survey, research issues and challenges. Comput Med Imaging Graph 2018; 65: 176-90.

9. Derwenskus J, Rucker JC, Serra A, Stahl JS, Downey DL, Adams NL, et al. Abnormal eye movements predict disability in MS: two-year follow-up. Ann N Y Acad Sci 2005; 1039: 521-3.

10. Samadani U, Farooq S, Ritlop R, Warren F, Reyes M, Lamm E, et al. Detection of third and sixth cranial nerve palsies with a novel method for eye tracking while watching a short film clip. J Neurosurg 2015; 122: 707-20.

11. Hwang CS, Weng HH, Wang LF, Tsai CH, Chang HT. An eye-tracking assistive device improves the quality of life for ALS patients and reduces the caregivers' burden. J Mot Behav 2014; 46: 233-8.

12. Inoue T, Masai N, Shiomi H, Oh RJ, Uemoto K, Hashida N. Feasibility study of a non-invasive eye fixation and monitoring device using a right-angle prism mirror for intensity-modulated radiotherapy for choroidal melanoma. J Radiat Res 2017; 58: 386-96.

13. Goodwin A, Salomone S, Bolton P, Charman T, Jones EJH, Pickles A, et al. Attention training for infants at familial risk of ADHD (INTERSTAARS): study protocol for a randomised controlled trial. Trials 2016; 17: 608.

14. Tien T, Pucher PH, Sodergren MH, Sriskandarajah K, Yang GZ, Darzi A. Eye tracking for skills assessment and training: a systematic review. J Surg Res 2014; 191: 169-78.

15. Kelly BS, Rainford LA, Darcy SP, Kavanagh EC, Toomey RJ. The development of expertise in radiology: in chest radiograph interpretation, "expert" search pattern may predate "expert" levels of diagnostic accuracy for pneumothorax identification. Radiology 2016; 280: 252-60.

16. Harrison TK, Kim TE, Kou A, Shum C, Mariano ER, Howard SK. Feasibility of eye-tracking technology to quantify expertise in ultrasoundguided regional anesthesia. J Anesth 2016; 30: 530-3.

17. Borg LK, Harrison TK, Kou A, Mariano ER, Udani AD, Kim TE, et al. Preliminary experience using eye-tracking technology to differentiate novice and expert image interpretation for ultrasound-guided regional anesthesia. J Ultrasound Med 2018; 37: 329-36.

18. Schulz CM, Schneider E, Kohlbecher S, Hapfelmeier A, Heuser F, Wagner KJ, et al. The influence of anaesthetists' experience on workload, performance and visual attention during simulated critical incidents. J Clin Monit Comput 2014; 28: 475-80.

19. King R, Hanhan J, Harrison TK, Kou A, Howard SK, Borg LK, et al. Using eye tracking technology to compare the effectiveness of malignant hyperthermia cognitive aid design. Korean J Anesthesiol 2018; 71: 317-22.

20. Jungk A, Thull B, Hoeft A, Rau G. Evaluation of two new ecological interface approaches for the anesthesia workplace. J Clin Monit Comput 2000; 16: 243-58.

21. Spaeth J, Schweizer T, Schmutz A, Buerkle H, Schumann S. Comparative usability of modern anaesthesia ventilators: a human factors study. Br J Anaesth 2017; 119: 1000-8. 